\title{
AVALIAÇÃO DE UMA PROPOSTA DE RECICLAGEM DE VEÍCULOS EM FIM DE VIDA NO PARANÁ BASEADA NO MODELO ALEMÃO ${ }^{1}$
}

\author{
Lucélia Mildemberger ${ }^{2}$ \\ Daniela Neuffer ${ }^{3}$ \\ Haroldo A. Ponte ${ }^{4}$ \\ Klaus Fischer ${ }^{5}$
}

- Enviado em 17/08/2015

- Aprovado em 10/09/2015

\begin{abstract}
RESUMO
O crescente volume de veículos em fim de vida (VFV) no mundo nas últimas décadas despertou a preocupação com a gestão ambientalmente correta desses resíduos. Desde a década de 90 na Comunidade Europeia (CE), EUA e Japão a preocupação com a recuperação dos materiais dos VFV começou a fazer parte da rotina. A Alemanha desempenhou desde o início um papel impulsionador para o mundo neste tema. No Brasil, no entanto, apesar do aumento de veículos que deixam de circular no país, o tema da reciclagem ainda não ocupou o devido destaque nas discussões entre governo, empresários e sociedade para estabelecer política e legislação específica. Sendo assim, o principal objetivo deste estudo foi buscar uma comparação entre a gestão de VFV no Paraná (PR) e em Baden-Württemberg (BW) na Alemanha referente ao período que antecede junho de 2012, data da defesa da dissertação. A partir do levantamento dos dados foram feitas análises comparativas para identificar oportunidades e limitações da proposta de reciclagem de veículos no PR.
\end{abstract}

Palavras-chave: Reciclagem de veículos. Regulamentação ambiental. Veículo em fím de vida.

\footnotetext{
${ }^{1}$ Dissertação defendida no Programa de Mestrado Profissional em Meio Ambiente Urbano e Industrial do Setor de Tecnologia da Universidade Federal do Paraná em parceria com o SENAI-PR e a Universität Stuttgart, Alemanha, em 15 de junho de 2012. Versão completa disponível na Biblioteca Digital da UFPR - http://hdl.handle.net/1884/28109.

2 Graduada em Administração pela FAE Business School. Mestre em Meio Ambiente Urbano e Industrial pela Universidade Federal do Paraná em convênio com o SENAI-PR e Universidade de Stuttgart. Endereço eletrônico: lucelia.mildemberger@hotmail.com.

${ }^{3}$ Doutora em Engenharia Civil e Ambiental pela Universität Stuttgart, Alemanha. Consultora, professora e pesquisadora da Universität Stuttgart, Alemanha.

${ }^{4}$ Doutor em Ciência e Engenharia dos Materiais - Departamento de Engenharia de Materiais da Universidade Federal de São Carlos (1994). Professor da Universidade Federal do Paraná.

${ }^{5}$ Doutor em Engenharia Civil e Ambiental pela Universität Stuttgart, Alemanha. Consultor, professor e pesquisador da Universität Stuttgart, Alemanha.
} 


\section{INTRODUÇÃO}

Em 2010 a produção mundial de automóveis leves e pesados chegou a 77.888.355 unidades (VDA, 2011a), aumentando quase $26 \%$ em relação ao ano anterior. O volume crescente de veículos absorvidos pelo mercado a cada ano provocou o surgimento da preocupação relativa ao destino dos veículos que saem de circulação e na busca de soluções para este problema. Na Europa estudos e discussões estão em desenvolvimento há duas décadas.

$\mathrm{Na}$ Alemanha o conceito de responsabilidade do produtor sobre o VFV chegou ao status de lei após um longo período de discussões e até mesmo de acordo voluntário entre fabricantes de automóveis, produtores, importadores e recicladores de partes e matéria-prima dentro do então conceito de Ecocycle Act (LUCAS, 2001).

Um dos resultados foi a criação da Diretiva 2000/53/CE (UNIÃO EUROPEIA, 2000), instrumento legal para a Comunidade Europeia que visa impor regras para a gestão de VFV destinado aos países membros. Esta diretiva foi transposta para o direito alemão na figura da Lei AltfahrzeugG e seu regulamento AltfahrzeugV (BMU, 2010).

Em 2009, a frota aproximada da Alemanha era de 45 milhões de veículos e foram destinados cerca de 1,7 milhões de VFV para o sistema de tratamento de resíduos automotivos ocupando a terceira posição em relação aos países membros da $\mathrm{CE}$ quanto aos resultados de reutilização e valorização dos VFV (BMU, 2011). A densidade de veículos neste país é de 1,8 habitantes por veículo (VDA, 2011b). A frota de veículos em BW em 2011 era de 7.040.776 veículos de passageiros e comerciais leves (ESCRITÓRIO DE ESTATÍSTICA DA ALEMANHA, 2012). A estimativa da densidade de veículos neste estado é de 1,5 habitantes por veículo.

No Brasil, os dados mostram a estimativa de que a frota brasileira seja composta por cerca de 32 milhões de veículos no total (ANFAVEA, 2011). De acordo com o DETRAN/PR (2010) a frota de veículos registrados no PR é composta por cerca de cinco milhões de veículos, sendo 47\% correspondente aos veículos com mais de dez anos de idade.

Os veículos com idade avançada, com maior quilometragem acumulada, apresentam diversos impactos ambientais relevantes, dentre os quais as emissões de poluentes. Por esta razão, foi criada a Resolução No 18 do CONAMA (Conselho Nacional do Meio Ambiente) em 06 de maio de 1986, que através da coordenação do IBAMA, estabeleceu o Programa de Controle de Poluição 
do Ar por Veículos Automotores - PROCONVE. Este programa definiu os primeiros limites de emissão para veículos leves (CONAMA, 1986). Em 28 de outubro de 1993 a Lei № 8723 endossou a obrigatoriedade de reduzir os níveis de emissão dos poluentes de origem veicular, contribuindo para induzir o desenvolvimento tecnológico dos fabricantes de combustíveis, motores e autopeças, e permitindo que veículos nacionais e importados, passassem a atender aos limites estabelecidos (BRASIL, 1993). Por essa razão, o PRONCOVE como instrumento da política ambiental brasileiro fez reduzir a emissão de poluentes veiculares dentre os quais o monóxido de carbono dos veículos leves. Em 1986, antes da implantação do programa, a emissão chegava a 50g/km em média nos veículos leves e o programa forçou uma redução de $50 \%$ já em sua primeira fase (L1) estabelecendo o limite de 24 gramas de $\mathrm{CO}$ por km rodado e esse limite ainda mais restrito passou a 1,3 gramas de CO por km rodado em 2013 (fase L6) conforme apresentado na Tabela 1.

TABELA 1 - ESTRATÉGIA DE IMPLANTAÇÃO DO PRONCOVE PARA VEÍCULOS LEVES (FASE "L")

\begin{tabular}{c|c|c}
\hline Fase & Implementação & Limites de CO (g/km) \\
\hline L1 & $1988-1991$ & 24 \\
\hline L2 & $1992-1996$ & 12 \\
\hline L3 & $1997-2004$ & 2 \\
\hline L4 & $2005-2008$ & 2 \\
\hline L5 & $2009-2013$ & 1,3 \\
\hline L6 & $2013-2015$ & 2 \\
\hline
\end{tabular}

Para conseguir reduzir as emissões foi necessário diminuir o consumo de combustível, o que foi possível, em grande parte, através da redução do peso dos veículos. Desta forma, a idade do VFV define suas características em termos das possibilidades de reciclagem e recuperação e refletem a mistura de materiais e diferentes critérios de design próprios das tecnologias disponíveis no momento da sua fabricação (Zoboli et al., 2000; Gerrard e Kandlikar, 2006).

Muitos outros impactos podem ser citados como a falta de segurança no trânsito e o aumento da dificuldade sobre a mobilidade causados pelos veículos antigos. Além disso, quando os VFV não recebem tratamento ambientalmente correto, caso dos veículos sinistrados armazenados indevidamente nos pátios da Polícia Rodoviária, ferros-velhos ou pátio do Detran, eles podem acumular água e por isso tornam-se criadouros do mosquito da dengue ou ainda, podem contaminar 
solo e água através de derramamento de gasolina, etanol ou óleos lubrificantes. Outro fator impactante é que o VFV representa em média uma tonelada de resíduos, entre eles os perigosos que precisam ser ambientalmente tratados (GHK, 2006).

\section{METODOLOGIA}

Os estados BW (Alemanha) e PR (Brasil) foram escolhidos como escopo deste estudo comparativo e a metodologia foi baseada nas atividades relacionadas abaixo:

a) levantamento da legislação referente à gestão de VFV na UE, Alemanha, BW, Brasil e PR foram realizadas para embasar as discussões referentes à reciclagem de VFV;

b) levantamento da situação da Alemanha quanto a aplicação dos procedimentos legais, técnicos e administrativos na reciclagem de VFV com foco no estado de $\mathrm{BW}$, baseado em visita técnica em uma empresa de shredder e uma empresa de coleta e desmontagem, que por estarem contidas num sistema padronizado como é na Alemanha representam bem a aplicação dos procedimentos de gestão de VFV, além de um questionário enviado para as empresas de desmontagem de VFV;

c) levantamento da situação do Brasil quanto a aplicação dos procedimentos legais, técnicos e administrativos na reciclagem de VFV com foco no PR, baseado em consultas aos sites oficiais, notícias e publicações.

\section{RESULTADOS}

O resultado da comparação dos procedimentos utilizados atualmente para a gestão de VFV em BW e no PR é descrito através de critérios legais, técnicos e administrativos.

A síntese dos aspectos gerais característicos dos estados BW e PR são apresentados no Quadro 1. 
QUADRO 1 - CARACTERÍSTICAS GERAIS DE BW E DO PR

\begin{tabular}{|c|c|c|}
\hline & Baden-Württemberg (Alemanha) & Paraná (Brasil) \\
\hline População (milhões de habitantes): & $\begin{array}{r}10,7 \\
\text { Fonte: BW (2012) }\end{array}$ & $\begin{array}{c}10,4 \\
\text { Fonte: IBGE (2012) }\end{array}$ \\
\hline Área $\left(\mathrm{km}^{2}\right)$ : & $\begin{array}{r}35.751 \\
\text { Fonte: BW (2012) }\end{array}$ & $\begin{array}{l}199.316 \\
\text { Fonte: PR (2012) }\end{array}$ \\
\hline Frota total de veiculos em 2010 (número de veiculos): & \begin{tabular}{|l}
\multicolumn{1}{c}{7.040 .776} \\
Fonte: SERVIÇO DE \\
ESTATÍSTICA DE BW (2012)
\end{tabular} & $\begin{array}{c}5.041 .846 \\
\text { Fonte: DETRANPR (2010) }\end{array}$ \\
\hline $\begin{array}{l}\text { Qtde média anual de veiculos com cancelamento de } \\
\text { registro (entre } 2007 \text { e 2010): }\end{array}$ & \begin{tabular}{l}
\multicolumn{1}{c}{73.888} \\
Fonte: SERVIÇO DE \\
ESTATÍSTICA DE BW (2012)
\end{tabular} & $\begin{array}{c}12.735^{1} \\
\text { Fonte: DETRANPR (2010) }\end{array}$ \\
\hline
\end{tabular}

${ }^{1}$ Falta a parcela não oficial e desconhecida

Fonte: $\mathrm{O}$ autor (2012)

Apesar de não haver dados estratificados por estado, tem-se que a idade média da frota de veículos de passageiros na Alemanha era de 8,2 anos em 2008 (ACEA, 2010) e no Brasil em 2010 era de 8,9 anos (SINDIPEÇAS, 2011).

Em 2010, na Alemanha, foram utilizados 44\% de sucata metálica na produção de 43,7milhões de toneladas de aço bruto (DERA, 2011). Enquanto no Brasil, no mesmo ano, foram utilizados $26,8 \%$ na produção de 32,8 milhões de toneladas de aço bruto sendo 6,4 milhões de toneladas de sucata de obsolescência e 2,3 milhões de toneladas de sucata de refugo de processo (INSTITUTO AÇO BRASIL, 2012).

Um único instrumento legal, a nível federal, disciplina a gestão de VFV em BW que é a Lei AltfahrzeugG. No PR, porém não existe um único instrumento legal à nível federal referente ao VFV como um todo, mas três resoluções e um decreto que disciplinam a gestão de partes dos VFV, sendo o Decreto $N^{\circ} 1305$ que regulamenta a Lei $N^{\circ} 8722$ que torna obrigatória a baixa do veículo como sucata (BRASIL, 1994), a Resolução No 362 que dispõe sobre o recolhimento, coleta e destinação final de óleo lubrificante usado ou contaminado (CONAMA, 2005), a Resolução $\mathrm{N}^{\circ} 401$ que inclui, além do tratamento ambientalmente adequado no fim de vida, limites máximos de chumbo, cádmio e mercúrio para as pilhas e baterias (CONAMA, 2008) e, por fim, a Resolução $\mathrm{N}^{\circ}$ 416 que dispõe sobre a degradação ambiental causada por pneus inservíveis e sua destinação ambientalmente adequada (CONAMA, 2009). A nível estadual, no PR, a Lei $\mathrm{N}^{\circ} 14.894$ proíbe a comercialização de peças de veículos sinistrados que sejam desmontados (PARANÁ, 2005).

Após um estudo realizado pelo Centro de Experimentação e Segurança Viária - CESVI (2010) a entidade sugere que uma das premissas para sustentar um programa de renovação de frota 
no Brasil seja o desenvolvimento de uma legislação específica que diga respeito exclusivamente à este tema, que englobe os governos federal, estadual e municipal e que inclua a fiscalização destas atividades.

O fluxo da reciclagem de VFV em BW inicia quando a operadora de desmontagem recebe o veículo, realiza a despoluição e a desmontagem de peças com potencial de revenda, bem como os componentes para reciclagem e segue até uma empresa de shredder onde acontece a trituração da sucata e a separação dos metais ferrosos e não ferrosos dos resíduos que não são recuperados. Tais etapas são apresentadas na Figura 1 (BERNINGER, 2005).

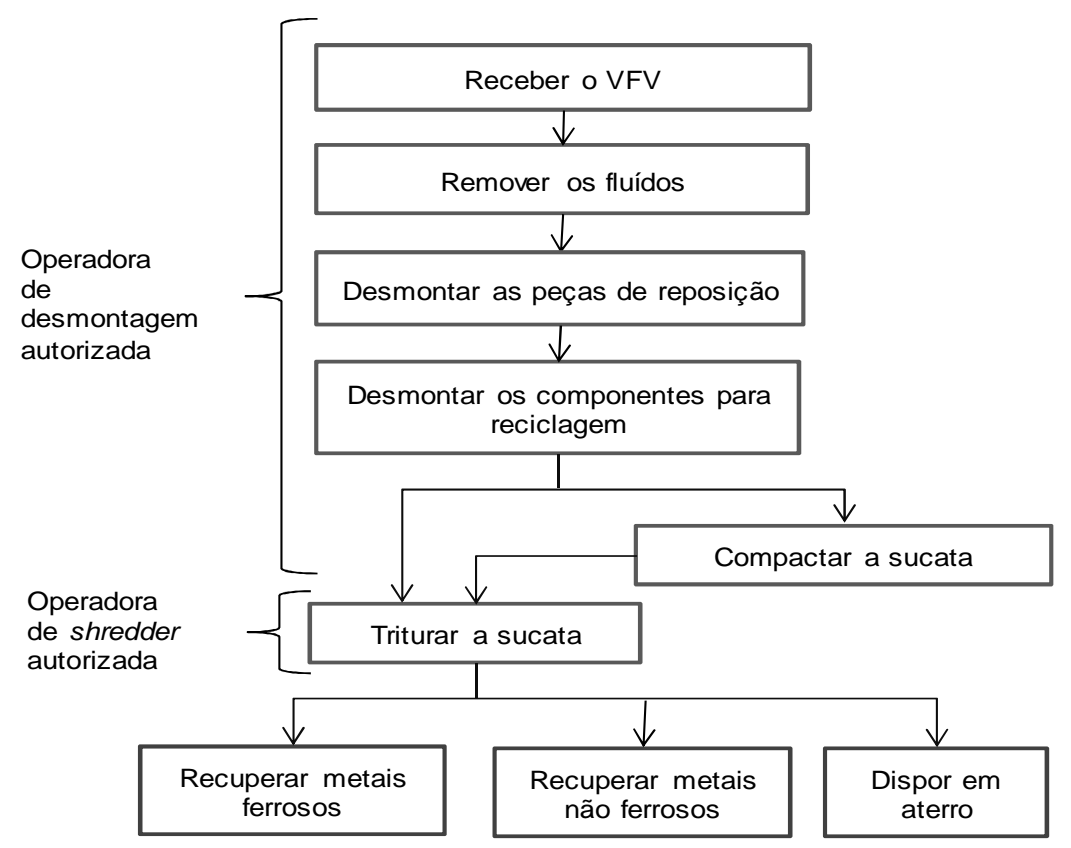

FIGURA 1 - FLUXO DE RECICLAGEM DE VFV EM BW Fonte: adaptado de BERNINGER (2005)

A solicitação de cancelamento do registro do veículo junto aos órgãos competentes de controle em BW é realizada pelo proprietário que deve apresentar o Certificado de Destruição do VFV para a entidade denominada Zulassungsstelle, órgão que emite o cancelamento de registro do veículo, sendo desconsiderada qualquer exigência quanto a idade do veículo. No caso do PR, para que o DETRAN/PR emita o Certificado de Baixa do Veículo, é necessária apenas uma solicitação formal que pode partir do proprietário, da autoridade policial no caso de veículo abandonado, da autoridade aduaneira quando o veículo sair do território brasileiro, do leiloeiro quando o veículo for alienado por seu intermédio ou da seguradora que haja efetuado a indenização do veículo segurado. Também no PR não há nenhuma imposição legal quanto à idade do veículo. 
A estimativa de fluxo de VFV no PR, de acordo com a Figura 2, apresentada de forma sintetizada, mostra as relações entre os organismos envolvidos no processo ainda de forma não estruturada onde veículos podem chegar a ser sucateados sem o cancelamento do registro, ou seja, sem o Certificado de Baixa de Registro junto ao DETRAN/PR.

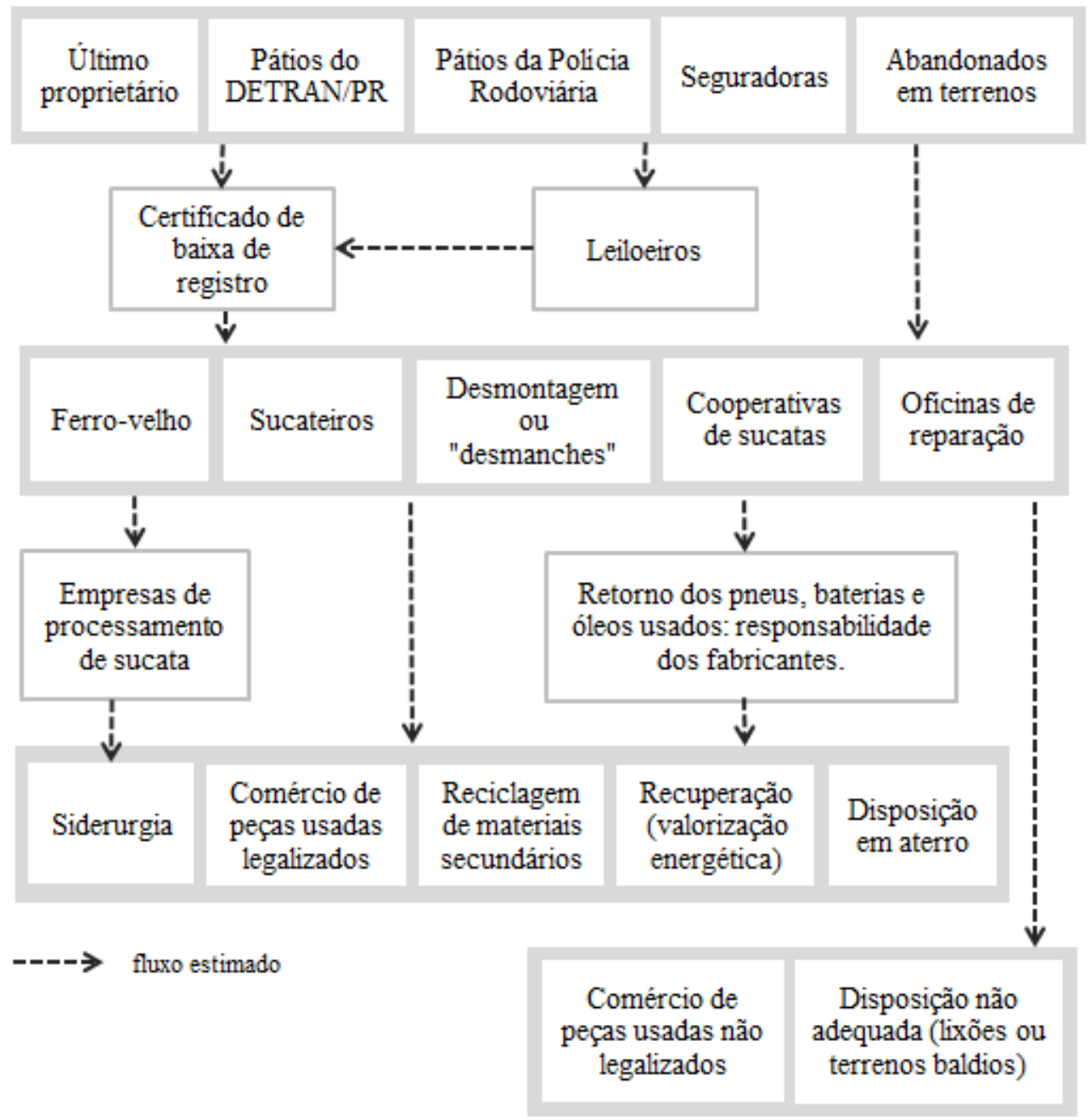

FIGURA 2 - FLUXO ESTIMADO DE GESTÃO DE VFV NO PR

Fonte: O autor (2012)

Em BW a Lei AltfahrzeugG impõem objetivos para a reutilização e reciclagem que deve ser $\geq 80 \%$ do peso do veículo e $\geq 85 \%$ para a reutilização e valorização. À partir de janeiro de 2015 os objetivos estabelecidos para a reutilização e reciclagem é $\geq 85 \%$ do peso do veículo e $\geq 95 \%$ para a reutilização e valorização. Nenhuma imposição legal neste sentido é feita no PR. 
Para atuarem no mercado de VFV as empresas em BW devem respeitar exigências impostas pela Lei AltfahrzeugG tais como a necessidade de certificação específica para processar os VFV com requisitos mínimos à cumprir. Por outro lado, no PR não existe nenhuma legislação que estabeleça exigências para as empresas que operam neste mercado.

A exigência imposta pela Lei AltfahrzeugG aos produtores e importadores de veículos quanto à entrega do VFV é disponibilizar uma rede de coleta autorizada de VFV a uma distância máxima de $50 \mathrm{~km}$ do proprietário, sem qualquer ônus, segundo o princípio da responsabilidade do produtor sobre o final de vida do produto.

Outras exigências legais impostas aos produtores e importadores de veículos são: a proibição de uso de substâncias perigosas como o cádmio, mercúrio, chumbo e cromo hexavalente na composição do veículo como abordado no item 2 do regulamento da Lei AltfahrzeugG, exceto para casos já descritos no anexo II da Diretiva 53/2000/CE; utilização de código padronizado para componentes e materiais utilizados no veículo como abordado no item 1 do mesmo regulamento; disponibilização das informações de composição dos veículos quanto à substâncias neles utilizadas abordado no item 2; disponibilização de informações para as operadoras de reciclagem de VFV para garantir uma desmontagem segura bem como testes, cuidados de manuseio e formas de armazenagem para as peças que podem ser reutilizadas como abordado no item 3. Exceto pela restrição de uso de substâncias perigosas nas baterias, nenhuma outra destas exigências é feita no PR.

Enquanto em BW estão disponíveis 170 empresas autorizadas para coleta e desmontagem e quatro empresas para o processamento de sucata metálica de VFV (ArGe-Altauto, 2011) no PR não há um número oficial das empresas que operam nesse mercado.

\section{DISCUSSÃO}

À partir de uma avaliação comparativa dos resultados apresentados é possível evidenciar as principais diferenças e similaridades na gestão dos VFV em BW e no PR.

O tamanho da população e a idade média da frota são similares, porém, a área do PR é cerca de seis vezes maior que BW e a densidade demográfica em BW é seis vezes maior do que no PR. A quantidade média anual de veículos cancelados no PR é quase seis vezes menor do que em BW, porém nem todos os veículos que deixam de circular no estado estão contemplados segundo o DETRAN/PR (2011). 
No Brasil existe um potencial de utilização de sucata no processo de produção de aço se considerado que está 17 pontos percentuais abaixo do percentual da Alemanha.

Quanto ao fluxo de gestão de VFV é evidente a falta de estrutura organizada no PR com fluxos de materiais conhecidos e controlados que promovam processos de tratamento ambientalmente corretos e seguros. Enquanto em BW os VFV são vistos como fonte de recursos secundários, no PR sequer são vistos como resíduos que devem ser corretamente tratados. Baseada nisso a proposta de fluxo da gestão de VFV para o PR é apresentada na Figura 3.

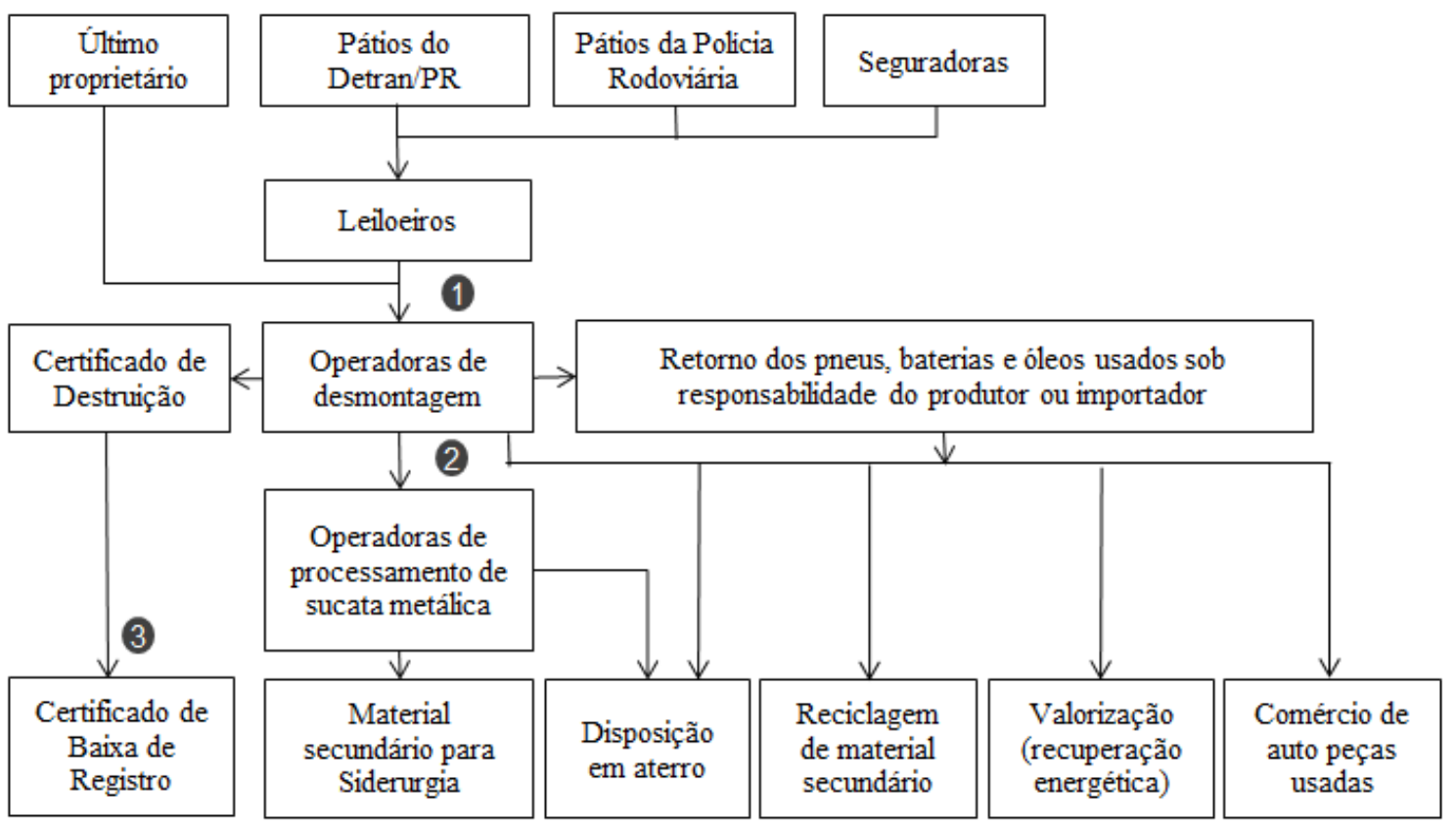

FIGURA 3 - FLUXO PROPOSTO PARA GESTÃO DE VFV NO PR Fonte: O autor (2012)

O fluxo proposto é baseado em três considerações, sendo:

1) O Certificado de Destruição é emitido pela operadora de desmontagem autorizada que recebe o VFV;

2) A operadora de desmontagem só pode encaminhar a sucata de VFV para uma operadora de processamento de sucata metálica autorizada juntamente com a cópia do Certificado de Destruição do veículo; 
3) O último proprietário deve apresentar o Certificado de Destruição ao DETRAN/PR para obter o Certificado de Baixa do Veículo, caso contrário, ele continua sendo o responsável pelos encargos devidos sobre o veículo.

Com base na avaliação comparativa sobre as exigências legais para que as empresas possam operar no mercado de VFV em BW, no PR quase nada é cobrado das empresas. A certificação das operadoras é uma ferramenta que ajuda o governo de BW a controlar de forma descentralizada as empresas que atuam neste mercado. Para obter o certificado, documento que autoriza a atividade, a empresa deve aplicar os requisitos definidos em lei.

Baseada nessas premissas, a proposta para o sistema de monitoramento da cadeia de operadores de VFV no PR apoia-se nas considerações explicadas abaixo:

1) Um órgão governamental de controle fica responsável por homologar e monitorar as empresas de certificação das empresas que processam VFV;

2) As empresas certificadoras que emitem o certificado para as empresas que operam na desmontagem e no processamento de sucata metálica de VFV, são obrigadas a fornecer ao governo a lista das empresas por elas certificadas bem como a cópia da Certificação ou na sua revogação o relatório da auditoria;

3) Os critérios para certificar as operadoras de desmontagem e de processamento de sucata metálica de VFV devem ser definidos em lei específica no PR;

4) A licença de operação das operadoras de desmontagem e de processamento de sucata metálica de VFV deve ser vinculada à certificação, cuja perda por não respeito aos requisitos definidos em lei implica na perda da licença de operação;

5) O certificado é válido por um período máximo de 18 meses. Um novo processo de certificação é necessário para renovar o certificado a cada 12 meses.

O sistema de monitoramento das operadoras que processam VFV proposto é apresentado conforme a Figura 4. 


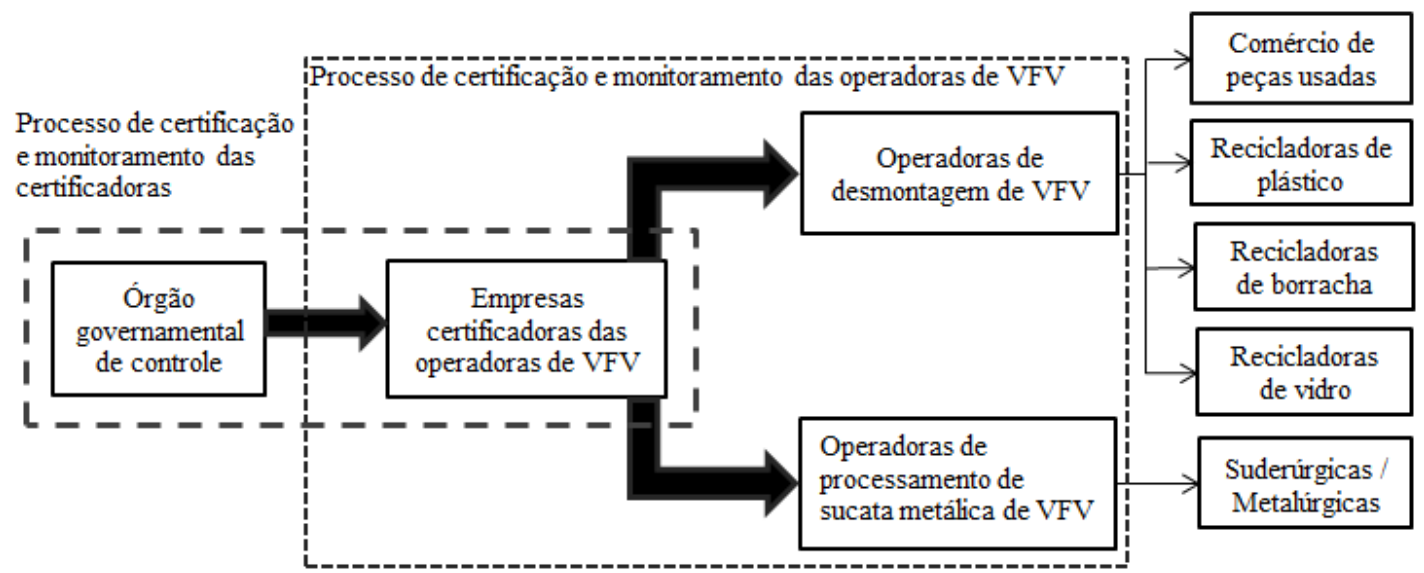

FIGURA 4 - PROPOSTA DE SISTEMA DE MONITORAMENTO DAS OPERADORAS QUE PROCESSAM VFV

Fonte: O autor (2012)

Em BW é aplicado o princípio da responsabilidade do produtor sobre o fim de vida do produto que deve disponibilizar pontos de coleta autorizados de VFV sem qualquer ônus ao proprietário. Diferente de BW, a legislação aplicada no PR disciplina a coleta e destinação de apenas algumas partes do veículo, sendo elas os pneus, baterias e óleos usados. Não havendo exigências legais para as demais peças retiradas dos VFV, ficam dúvidas sobre a correta destinação que as outras partes deveriam ter.

As exigências legais para os produtores e importadores de veículos quanto à composição e disponibilização de informações sobre os veículos no PR não tem a mesma relevância que tem em BW. O papel do fabricante é importante na adequação dos veículos para atingir os índices de reutilização, reciclagem, valorização e disposição final e pode ser no PR, como é em BW, realizado através do instrumento legal que disciplina a homologação do veículo (UNIÃO EUROPEIA, 2005). As preconizações de desmontagem do VFV garantem a segurança e qualidade das peças comercializadas e sua aplicação é verificada através do processo de certificação.

Em BW o proprietário é responsável pelo veículo e seus encargos até cancelar o registro junto ao órgão competente. Ao contrário, no PR a falta de um documento para oficializar a sua destruição representa uma lacuna na legislação que faz com que veículos que já deixaram de circular sejam ainda considerados na frota divulgada pelo DETRAN/PR.

O que pode ser ressaltado é que a legislação para a gestão de VFV no PR é fragmentada com diferentes procedimentos legais ligados ao tema o que dificulta o seu controle e aplicação enquanto que em BW uma única lei disciplina o tema. 


\section{CONSIDERAÇÕES FINAIS}

Considerando o levantamento realizado conclui-se que a gestão de VFV no PR é conduzida de forma descontrolada onde são recuperados somente materiais com valor de mercado sem qualquer preocupação com os riscos de segurança, ambientais e de saúde. Ao contrário do que acontece em BW, a cadeia de empresas é desagregada e sem relações comerciais definidas. Quanto às operações de coleta, despoluição e desmontagem, o número de empresas no PR é indeterminado e é composto por ferros-velhos, sucateiros entre outros.

Com a lacuna legal a maioria das operações ligadas à VFV não são padronizadas e controladas no PR e podem levar a práticas indevidas que representam riscos para a sociedade. Ao contrário da legislação exclusiva para VFV aplicada em BW, as legislações aplicadas no PR, são fragmentadas e referem-se à componentes específicos do veículo como pneus, baterias e óleos usados enquanto as partes restantes ficam descobertas de disciplina legal. A lei do PR, que pretende disciplinar o comércio de autopeças de VFV é restrita e não contempla os requisitos estabelecidos pela regulamentação aplicada em BW.

Como em BW a responsabilidade do proprietário deve se estender até o cancelamento do registro junto ao órgão competente usando para isso o Certificado de Destruição, por isso é necessário que a legislação paranaense seja revisada. A entrega do VFV à uma empresa de desmontagem autorizada, atrelada ao Certificado de Destruição, evita discrepâncias entre a situação do VFV e o registro no DETRAN/PR. É necessário também que a legislação do PR que prevê a isenção de pagamento de IPVA para veículos com mais de 20 anos através da Lei 14.260 (PARANÁ, 2003) seja revista, pois esta isenção exerce influência negativa sobre um programa orientado para a reciclagem de veículos.

A implantação, no PR, de um sistema de coleta autorizado, como aplicado em BW, pode aumentar a garantia de que os VFV sejam destinados de forma controlada, ambientalmente correta e mais segura à um sistema de reciclagem. O desenvolvimento de uma cadeia de empresas com capacidade física e tecnológica para receber, transportar e processar os materiais oriundos de VFV no PR para a reciclagem e valorização é fundamental. A implantação das propostas apontadas neste estudo poderia resultar em ganhos para a sociedade, como a redução da criminalidade referente ao "furto encomendado" de veículos que abastecem o mercado paralelo de peças automotivas, o aumento da segurança para os motoristas e passageiros com a redução de assaltos para roubo de veículos, melhores condições de saúde para as pessoas que trabalham no manuseio de peças ou partes dos VFV, facilitar a mobilidade urbana tirando veículos sem condições devidas de rodagem 
das vias públicas e melhoria no meio ambiente com a redução do nível de emissões de poluentes. Já para as empresas, a vantagem seria o desenvolvimento de novos negócios, a profissionalização dessa atividade e o possível aumento da lucratividade. E o estado pode ganhar com o aumento da arrecadação pela legalização das atividades e a redução de custos com o controle da criminalidade, com o transporte e armazenamento de veículos abandonados, e com a diminuição dos custos com acidentes causados por veículos sem condições de rodagem. E por fim, outra vantagem seria a melhoria na confiabilidade do banco de dados relativo à frota de veículos do estado controlado pelo DETRAN-PR.

\section{REFERÊNCIAS BIBLIOGRÁFICAS}

ACEA.(Association des Constructeurs Européens d'Automobiles). Average Car Age in Europe. 2010. Disponível em: <http://www.acea.be > Acesso em: 06 mar. 2012.

INSTITUTO AÇO BRASIL. Anuário estatístico. 2012.

ANFAVEA. (Associação Nacional dos Fabricantes de Veículos Automotores). Anuário da Indústria Automobilística Brasileira. SP. 2011.

ARGE-ALTAUTO. (Auto Recycling Gebrauchte Ersatzteile). Portal de informações sobre VFV na Alemanha. 2011. Disponível em: <http://www.arge-altauto.de/index.php?seite=nachrichten > Acesso em: 14 jan. 2012.

BERNINGER, B. Anforderungen na Demontagebetriebe. Demontage und Verwertung von Altfahrzeugen. Bayeriches Landesamt für Umwelt. Augsburg. 2005.

BMU. (BUNDESMINISTERIUM FÜR UMWELT, NATURSCHULTZ UND REAKTORSICHERHEIT). End-of-life vehicle reuse/recycling/recovery rates in Germany for 2009 pursuant to Art. 7 (2) of the End-of-life vehicles Directive 2000/53/EC. Jun. 2011. Disponível em: <http://www.bmu.de/files/english/pdf/application > Acesso em: 30 dez. 2011.

BMU. (BUNDESMINISTERIUM FÜR UMWELT, NATURSCHULTZ UND REAKTORSICHERHEIT). General Information Waste Management in Germany. Set. 2010. Disponível em: <http://www.bmu.de/english/waste_management> Acesso em: 10 maio 2012.

BRASIL. Decreto Nº 1.305. Diário Oficial da União, Seção I, p. 16852. 1994.

BRASIL. Lei No 8.723, de 28 de outubro de 1993. Dispoe sobre a redução de emissão de poluentes por veículos automotores e dá outras providências. DOU, Seção I, p. 16313. 1993.

BW. (BADEN-WÜRTTEMBERG). Facts and Figures. Disponível em: <http://www.badenwuerttemberg.de/en/Our_State > Acesso em: 05 abr. 2012.

CESVI. Inspeção técnica veicular, manutenção preventiva e renovação de frota; fatores chave para o trânsito brasileiro. Revista Cesvi. Ano 13. № 67. 2010. 
CONAMA - Conselho Nacional do Meio Ambiente. Resolução $\mathrm{N}^{\mathrm{o}}$ 18, Ministério do Meio Ambiente, de 17 de junho de 1986. Brasília: DOU de 17/6/1986.

CONAMA - Conselho Nacional do Meio Ambiente. Resolução No 362, Ministério do Meio Ambiente, Diário Oficial da União, n. 121, seção I, p. 128-130, Brasília, DF, 2005.

CONAMA - Conselho Nacional do Meio Ambiente. Resolução No 401, Ministério do Meio Ambiente, Diário Oficial da União, n. 215, seção I, p. 108-109, Brasília, DF, 2008.

CONAMA - Conselho Nacional do Meio Ambiente. Resolução No 416, Ministério do Meio Ambiente, Diário Oficial da União, n. 188, p. 64-65, Brasília, DF, 2009.

DERA. (Deutsche Rohstoffagentur). Deutschland Rohstoffsituation. 2011. Disponível em: <http://www.deutsche-rohstoffagentur.de/DE/Gemeinsames > Acesso em: 23 fev. 2012.

DETRAN/PR. (Departamento de Trânsito do Paraná). Anuário estatístico. 2010.

DETRAN/PR. (Departamento de Trânsito do Paraná). Anuário estatístico. 2011.

ESCRITÓRIO FEDERAL DE ESTATÍSTICA DA ALEMANHA. (Statistisches Ämter des Bundes und der Länder). 2012. Disponível em: <http://www.statistik-portal.de/StatistikPortal/en/en_jb16_jahrtab37.asp> Acesso em: 16 fev. 2012.

GERRARD, J.; KANDLIKAR, M. Is European end-of-life vehicle legislation living up to expectations? Assessing the impact of the EVL Directive on "green" innovation and vehicule recovery. Journal of Cleaner Production, Netherlands, v.16, p.432-449, nov. 2006.

GHK. A study to examine the benefits of the End of Life Vehicles Directive and the costs and benefits of a revision of the 2015 targets for recycling, re-use and recovery under the VFV Directive. $2006 . \quad$ Disponível em: <http://ec.europa.eu/environment/waste/pdf/study/final_report.pdf> Acesso em: 18 jan. 2012.

IBGE. ESTADOS. Disponível em : <http://www.ibge.gov.br/estadosat/perfil.php?sigla=pr > Acesso em: 13 fev. 2012.

LUCAS, R. End-of-life vehicle regulation in Germany and Europe - problems and perspectives. Wuppertal Institut für Klima, Umwelt und Energy. 2001.

MMA. (Ministério do Meio Ambiente). $1^{\circ}$ Inventário nacional de emissões atmosféricas por veículos automotores rodoviários - Relatório Final. Brasil. 2011.

PARANÁ. Lei No 14.260. Diário Oficial n. 6632. Curitiba. PR. 2003.

PARANÁ. Lei No 14.894. Diário Oficial n. 7099. Curitiba. PR. 2005.

Serviço de Estatística de BW. <http://www.statistik.baden-wuerttemberg.de/UmweltVerkehr/ > Acesso em: 07 mar. 2012. 
SINDIPEÇAS. Levantamento da frota circulante brasileira. Abril de 2011. Disponível em: <www.sindipecas.org.br> Acesso em: 21 out. 2011.

UNIÃO EUROPEIA. Diretiva 2000/53/CE do Parlamento Europeu e do Conselho, de 18 de setembro de 2000. Relativa aos veículos em fim de vida. JORNAL OFICIAL DA UNIÃO EUROPEIA (JO), L 269, p. 34-43, 2000.

UNIÃO EUROPEIA. Diretiva 2005/64/CE do Parlamento Europeu e do Conselho, de 26 de outubro de 2005. Relativa à homologação de veículos automotores com vista à reutilização, reciclagem e valorização. JORNAL OFICIAL DA UNIÃO EUROPEIA (JO), L 310, p. 10-27, 2005.

VDA. (Verband der Automobilindustrie). Automobile Production. 2011a. Disponível em: <http://www.vda.de/en/zahlen/jahreszahlen/automobilproduktion > Acesso em: 21 out. 2011.

VDA. (Verband der Automobilindustrie). Vehicles on the road. 2011b. Disponível em: <http://www.vda.de/en/zahlen/jahreszahlen/kfz_bestand > Acesso em: 21 out. 2011.

ZOBOLI, R.; BARBIROLI, G.; LEONCINI, R.; MAZZANTI, M.; MONTRESOR, S. Regulation and innovation in the area of end of life vehicles. Milão. 2000.

\title{
ASSESSMENT OF AN END OF LIFE VEHICLES RECICLYNG PROPOSE IN PARANÁ BASED ON GERMAN MODEL
}

\begin{abstract}
The growing volume of end-of-life vehicles (ELV) in the world in recent decades aroused the concern with the environmentally correct management of this kind of waste. Since the 90's, concern about the recovery of end-of-life materials began to be a routine in many countries of the European Community, Japan and the U.S.A. Germany has played a major role leading the world on this issue. In Brazil, despite the increase of number of vehicles that are no longer on the streets, the issue of recycling has not been taken as seriously as it should due to on-going discussions between government, businesses and society to establish the proper policies and specific legislation required. Based on this, the main objective of this study was to make a comparison between Paraná (PR) and a state experienced in the recycling of ELV. Therefore was the chosen state was Baden-Württemberg (BW) in Germany. The survey date refers to period before June of the year 2012. From the survey data, comparative analyses were done in order to highlight the discrepancies and identify opportunities and constraints of a recycling propose for vehicles in PR.
\end{abstract}

Keywords: Vehicles recycling. Environmental legislation. End-of-life vehicles. 